\title{
An Educational Game in Collaborative Logistics
}

\author{
Sophie D'Amours ${ }^{1}$ and Mikael Rönnqvist ${ }^{2}$ \\ ${ }^{1}$ Université Laval, Québec City, Québec, G1V 0A6, Canada \\ ${ }^{2}$ Norwegian School of Economics and Business Administration, Helleveien 30, \\ NO-5045 Bergen, Norway \\ Sophie.DAmours@cirrelt.ca, Mikael.Ronnqvist@nhh.no
}

\begin{abstract}
We describe an educational game in collaborative logistics. The game is based on an award winning application in cost allocation in forest transportation. The purpose of the game is to get an understanding of negotiation, coalition building and cost/profit sharing when the players have different power and hold different levels of information. The game is played with each player representing a single company. The objective of the game is to find an efficient plan and to share the benefits of the collaboration. We outline the game and discuss experiences from running the game in several countries and with students registered in business schools, engineering and forestry faculties.
\end{abstract}

Keywords: Collaborative Logistics, Cost sharing, Cooperative game, Logistics.

\section{Introduction}

In order to beat the competition, access new markets and respect operational, social and environmental constraints, enterprises establish more and more collaborations with many other business entities. Furthermore, with costs and information sharing, organizations have the opportunity to optimize their logistics activities. However, each enterprise has its own objectives and typically makes its own planning decisions to maximize individual profit. Therefore, it becomes crucial to determine how business entities will work together, the value of the collaboration and how to share the benefits. In order to illustrate the behavior when companies are faced with the task of sharing information and agree on sharing of benefits, we have developed an educational game. The game is based on an industrial case described in Frisk et al. (2010). This article won the EURO Management Science Strategic Innovation Price 2007. The game is easy to understand and can be used in many logistics or quantitative courses and for many different students. We have used it for Master students at business schools, engineering schools and professionals in transportation planning. In addition, we have used it in several countries including Sweden, Norway, Canada, France and Chile.

A popular and well used educational game is the "beer distribution game" (beer game) developed at MIT (Sterman, 1989). It is a simulation game to illustrate the impact of the bullwhip effect in supply chains. It serves to identify best practices in supply chain management. There are also electronic versions of the game, see e.g. Simchi-Levi et al. (2003). The beer game has also been adopted and implemented for 
different sectors, for example, the FORAC Research Consortium had developed an online version for the forest industry. The importance and positive effect to use business games as teaching tools in Management Science (MS) and Operations Research (OR) courses are discussed in Griffin (2007) and Ben-Zvi and Carton (2007). It is argued that business games are an effective way to engage students in MS/OR topics. It provides an understanding of the real problem and the practical situation faced by the companies or organizations where the problems exist. There exist games for several industrial sectors. Recently, Talluri (2009) described a game for teaching revenue management and Allon and Mieghem (2010) described one for supply chain sourcing. A general list of on-line simulation games is described in Wood (2007).

In this paper, we describe how the game can be played and report on some general observations. A lecture where the game is played is divided into four parts. In the first part, the background of the case study and setting of the game is introduced. In the second and third part, the game is played in two runs. In the first run, a restricted game is played, where the number of participants in the collaboration is limited. In the second run, any collaboration is allowed. In the last fourth part, the results and experiences of the real case study is described and discussed. The outline of the paper is as follows. In Section 2, we describe the case study used in the game. In Section 3, we describe some material used to play the game. In Section 4, we describe experiences from running the game in different settings. We end with some concluding remarks.

\section{Case Study}

The data used in this paper has been taken from a study done by the Forestry Research Institute of Sweden for eight participating forest companies. These companies operate in the southern part of Sweden as shown in Figure 1. The green area is the location of supply areas and the stars are industries. In total there are 898 harvest areas and 101 industries. The total number of products (or assortments) is 39. A product is a $\log$ with specific combination of species, diameter, length and quality. Demand is either expressed as a volume per product or as a volume of a mix of products (there are 12 possible products mix).

In our case we consider the problem of coordinating fiber procurement and transportation for several companies. It is common that transport costs can be decreased if companies use wood bartering. However, this is difficult as planners do not want to reveal supply, demand and cost information to competitors. In practice, this is solved by deciding on wood bartering of specific volumes. Today, this is typically done in an ad-hoc manner and is mostly dependent on personal relations. In Figure 2, we illustrate the potential benefits of wood bartering when two companies are involved. Here, we have four mills at two companies (two mills each) together with a set of supply points for each company. On the left hand side, each company operates by itself. The transportation distances are relatively long as compared to the right side where all supply and demand points are used by both companies. Since the overall cost is more or less proportional to the distance, it is clear that the solution to the right side with collaboration is much better than the left side without collaboration. 


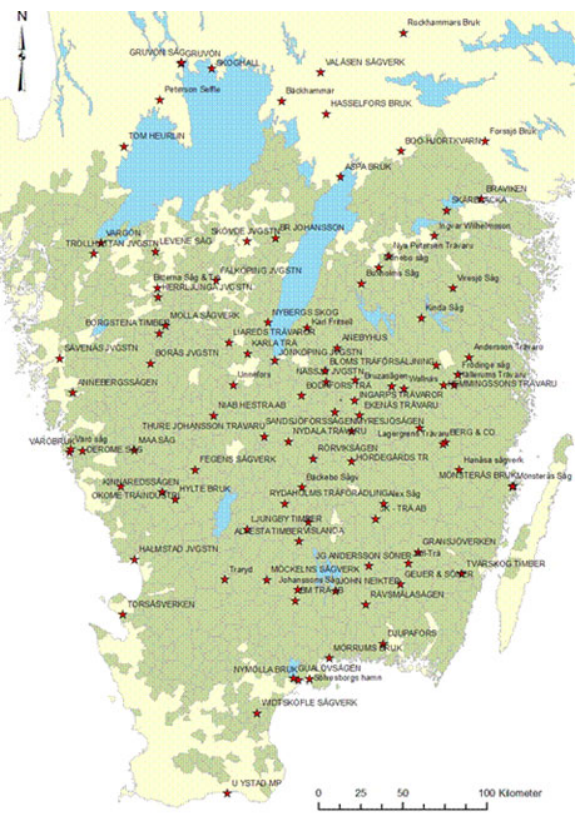

Fig. 1. Illustration of geographical area where the companies operate in southern Sweden
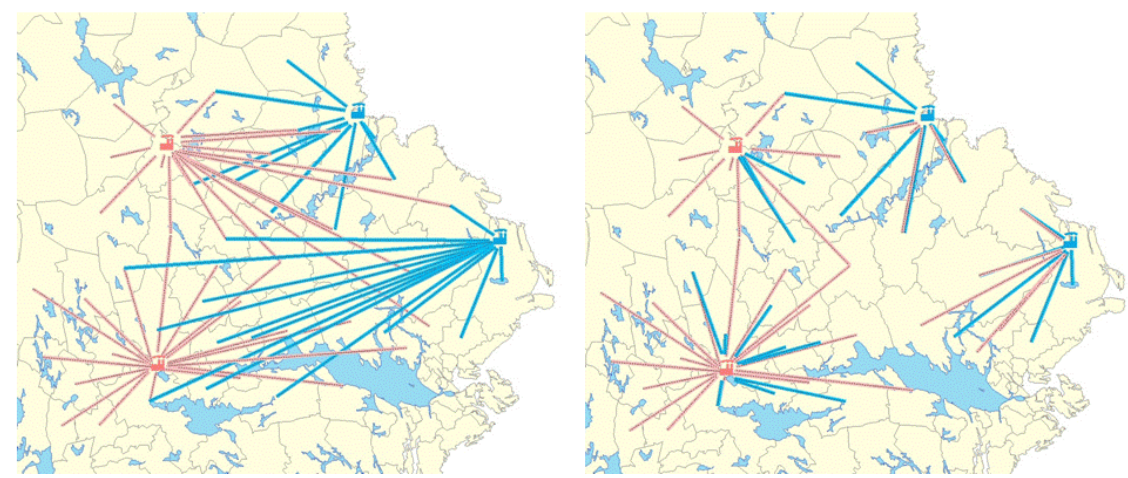

Fig. 2. Illustration of wood bartering between two companies. In the left part, two companies (indicated in blue and red) work with their own supply and demand. In the right part, the companies treat their supply and demand as common.

The data to support the case study is taken from transportation files reporting on activities carried out during one typical month. It involves all transports from the eight companies and includes information on time, from/to nodes, volume and product. The level of activities varies within the companies. Table 1 shows the volume transported and the proportion over the total transported volume for each of the companies. It is clear that company 2 is much larger than company 8 . This aspect and its consequences will be very clear in the game. 
Table 1. Monthly volumes (cubic meters) for each of the eight companies

\begin{tabular}{rrr}
\hline Company & Volume & Proportion \\
\hline Company 1 & 77361 & $8.76 \%$ \\
Company 2 & 301660 & $34.16 \%$ \\
Company 3 & 94769 & $10.73 \%$ \\
Company 4 & 44509 & $5.04 \%$ \\
Company 5 & 232103 & $26.29 \%$ \\
Company 6 & 89318 & $10.12 \%$ \\
Company 7 & 36786 & $4.17 \%$ \\
Company 8 & 6446 & $0.73 \%$ \\
\hline
\end{tabular}
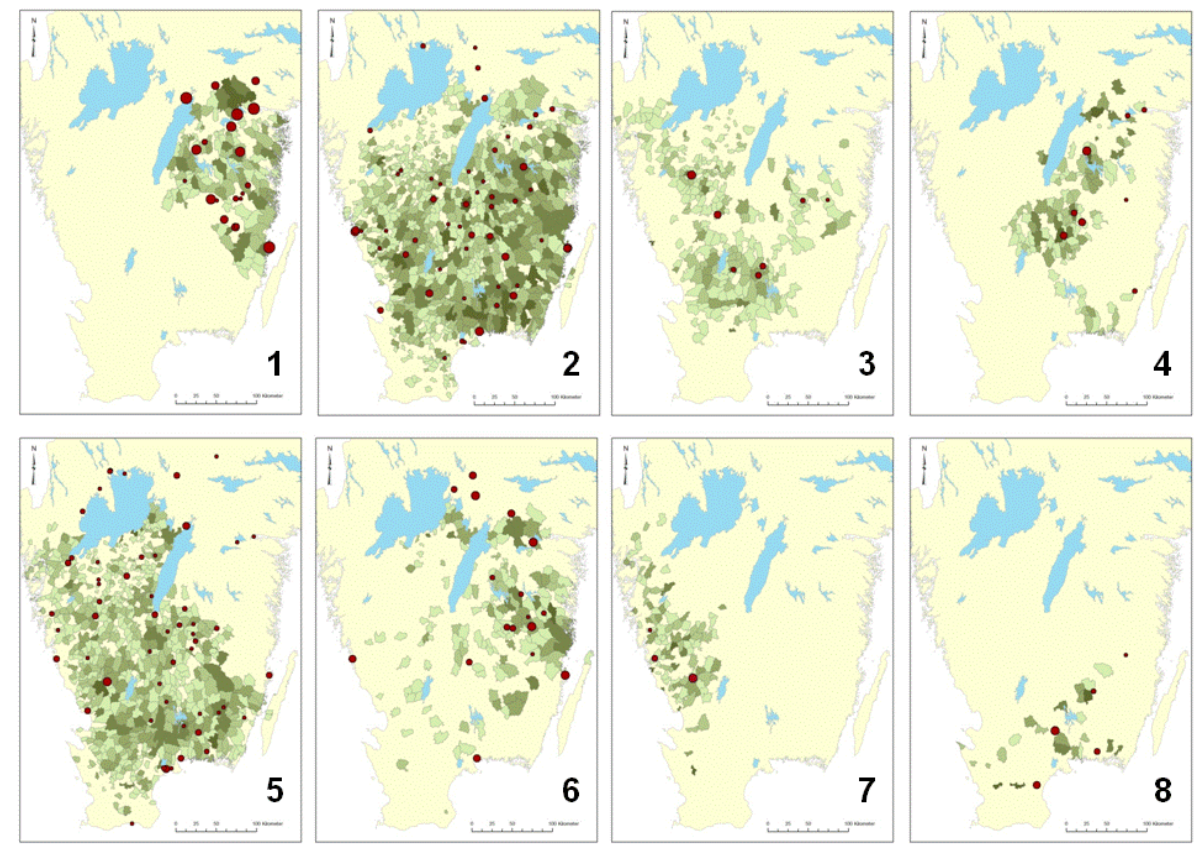

Fig. 3. Supply areas (indicated with green) and demand points or mills (indicated with red circles) for the companies

The companies operate in southern Sweden and cover different geographical areas; see Figure 2 where the green areas show the supply areas and the red circles denote the industries. Some companies cover the entire region (e.g. company 2) and others only a part (e.g. company 1). A good coverage, i.e. they work in the same region, between two companies indicates high potential for savings. For example, if companies 2 and 5 collaborate the cost savings can be large. At the same time, if companies 1 and 5 collaborate the cost savings would be small. 
From the case study, we had detailed information on all transports made by the eight companies. With this information, we can compute the optimal cost for each company as well as the cost if all eight companies work together. In addition, we can also compute the cost of all possible coalitions. There are $245\left(2^{8}-1-8\right)$ coalitions possible. The new transportation costs were computed with the system FlowOpt (Forsberg et al. 2005). This is a decision support system which includes a Geographical Information System, the Swedish road database NVDB and optimization routines to solve the OR models. The transportation planning problem is to decide how to transport logs from supply to demand point. The transportation can be done directly or indirectly through terminals. Moreover, there are several transportation modes including trucks, trains and ships. In Table 2, we provide information of the actual cost of the transportation activities, the cost when transportation is optimized within the company and finally, the cost when all companies are working together. The total saving when all companies are working together is $8.6 \%$. In the game, we use only the optimized values as the companies may have different efficiency in their own planning.

Table 2. Real and optimized costs associated with each company and when all work together. All cost units are given in kSEK (thousand of Swedish kronor).

\begin{tabular}{rrrr}
\hline Company & Cost - real & Cost - opt & Cost - all \\
\hline Company 1 & 3,894 & 3,778 & \\
Company 2 & 15,757 & 14,859 & \\
Company 3 & 4,828 & 4,742 & \\
Company 4 & 2,103 & 2,067 & \\
Company 5 & 10,704 & 10,340 & \\
Company 6 & 5,084 & 4,959 & \\
Company 7 & 1,934 & 1,884 & \\
Company 8 & 333 & 333 & 39,253 \\
Companies 1-8 & & & 39,253 \\
Total & 44,637 & 42,963 & \\
\hline
\end{tabular}

\section{Game}

The game can be played in two versions. The first version include four companies and the second all eight companies. In the version with four companies more information is provided to the players. Most important is the actual costs of the all possible coalitions. Both versions of the game are played during a lecture of 2-3 hours. In a standard class, there will be a set of groups of four students. The information provided for the students in version 1 is given below.

The purpose of this collaboration game is to establish an agreement in how four companies should organize themselves and divide the overall cost and the potential 
savings. Each company has a supply and demand for a set of products in balance, see Figure 4, and the cost arises when the supply is transported to the demand locations. Each company can work individually and has a specific transportation cost. The costs are found by using an optimization model which minimizes the cost given supply and demand. A summary of the companies when they are working individually during one month is given in Table 3 .
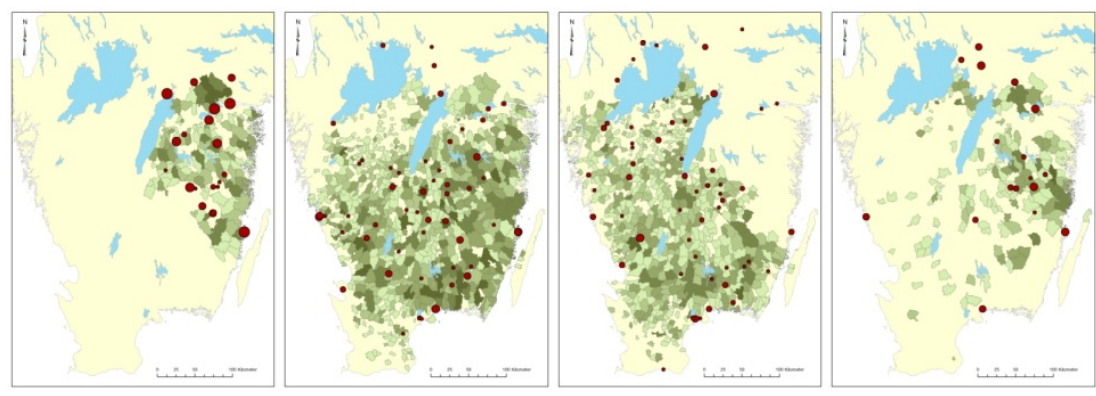

Fig. 4. Maps describing each of the four companies $\mathrm{C} 1-\mathrm{C} 2-\mathrm{C} 3-\mathrm{C} 5$. Green areas describe supply areas and red circles industries with demand.

Table 3. Summary of the four companies and their transportation volume, transportation cost and average transportation distance

\begin{tabular}{rrrr}
\hline Company & Volume & Individual cost & Average distance \\
\hline Company 1 & $77,300 \mathrm{~m}^{3}$ & $3,780(\mathrm{kSEK})$ & $70,3 \mathrm{~km}$ \\
Company 2 & $301,300 \mathrm{~m}^{3}$ & $14,860(\mathrm{kSEK})$ & $56,8 \mathrm{~km}$ \\
Company 3 & $232,100 \mathrm{~m}^{3}$ & $10,340(\mathrm{kSEK})$ & $68,5 \mathrm{~km}$ \\
Company 5 & $89,300 \mathrm{~m}^{3}$ & $4,960(\mathrm{kSEK})$ & $68,5 \mathrm{~km}$ \\
Total & $700,000 \mathrm{~m}^{3}$ & $33,940(\mathrm{kSEK})$ & $-\cdots$ \\
\hline
\end{tabular}

The companies can form one or several coalitions (a set of companies working together). If they work in a coalition, they simply treat their supply and demand as common, and can find a solution that lowers the overall transportation cost. For example, if companies $\mathrm{C} 1$ and $\mathrm{C} 2$ work individually, the overall cost is 3,780 (C1) + $14,860(\mathrm{C} 2)=18,640 \mathrm{kSEK}$. However, if they work together, the cost is $18,300 \mathrm{kSEK}$ which represent a saving of $340 \mathrm{kSEK}(18,640-18,300)$. One question is how these $340 \mathrm{kSEK}$ should be divided between the two companies $\mathrm{C} 1$ and $\mathrm{C} 2$. There are many possible coalitions and Table 4 summarizes their costs and savings. The improvement in the table is given as percentage i.e. savings divided by the the aggregated individual cost. For example, the improvement for coalition $(\mathrm{C} 1+\mathrm{C} 2+\mathrm{C} 3)$ is computed as $1,270 / 28,980=4.38 \%$. 
Table 4. Summary of possible coalitions sand their cost if they work together, summed individual cost, saving and improvement

\begin{tabular}{cccc}
\hline Coalition & $\begin{array}{c}\text { Cost }(\mathrm{kSEK}) \\
\text { (collaboration) }\end{array}$ & $\begin{array}{c}\text { Cost }(\mathrm{kSEK}) \\
\text { (individual) }\end{array}$ & Saving $(\mathrm{kSEK})$ \\
\hline$C 1+C 2$ & 18,300 & 18,640 & 340 \\
$C 1+C 3$ & 14,000 & 14,120 & 120 \\
$C 1+C 5$ & 8,510 & 8,740 & 230 \\
$C 2+C 3$ & 24,210 & 25,200 & 990 \\
$C 2+C 5$ & 19,040 & 19,820 & 780 \\
$C 3+C 5$ & 15,060 & 15,300 & 240 \\
$C 1+C 2+C 3$ & 27,710 & 28,980 & 1,270 \\
$C 1+C 2+C 5$ & 22,490 & 23,600 & 1,110 \\
$C 1+C 3+C 5$ & 18,580 & 19,080 & 500 \\
$C 2+C 3+C 5$ & 28,400 & 30,160 & 1,760 \\
$C 1+C 2+C 3+C 5$ & 32,000 & 33,940 & 1,940 \\
\hline
\end{tabular}

\section{Assignments}

In the collaboration game, each group consists of four players. Each player is responsible for one company. The objective for each player is to improve its own cost/profit as much as possible. The task is to discuss and agree which companies should work together (if any). In part A only two companies can work together. In part B any coalition structure is possible. For example, all companies can work together, no companies work together, any group of two or three companies can work together. Each company can only participate in one coalition (in both part A and part B). Given the agreed coalitions in the two parts, how should the overall savings be divided among the participating companies?

Once the first part is played, we have a discussion on how the participant made their decisions, their thinking and their bargaining power. We also discuss the different results (displayed for groups) that the students have agreed on. This discussion is often interesting and provides a good basis for the second part.

The information provided for the students in version 2 is different. Each company has information about its total cost together with the information about collaborating with one other company. There is no information on collaborating with three or several companies. In this version, it is more important to find agreements without knowing the real benefits. Below in Table 5, we provide the information for one company. Version 2 also has two parts. In the first part, coalitions of at most two companies should be found. This is more difficult, as compared to version 1, as there are many more alternatives. Also, here it is very clear that companies 2 and 5 have much higher negotiation power. In the second part, any coalition and principle for sharing the benefit is to be found. At the end, the real benefits of the agreed coalitions are provided to the agreed groups and they need to split the savings according to the agreed principles. 
Table 5. Costs and savings (kSEK) when company 1 works together with a second (2-8) company

\begin{tabular}{ccrrr}
\hline Company & Company & Cost (separate) & Cost (together) & \multicolumn{1}{c}{ Saving } \\
\hline 1 & 2 & 18,640 & 18,300 & 340 \\
1 & 3 & 8,520 & 8,490 & 30 \\
1 & 4 & 5,840 & 5,770 & 70 \\
1 & 5 & 14,120 & 14,000 & 120 \\
1 & 6 & 8,740 & 8,510 & 230 \\
1 & 7 & 5,660 & 5,660 & 0 \\
1 & 8 & 4,110 & 4,100 & 10 \\
\hline
\end{tabular}

Once the game is played, we follow up with what happened in the real case and what sharing mechanisms were tested and used. We introduce the students to basic game theory including the core conditions, efficient allocation and individual rationality concepts. We then go through well known methods such as the Shapley value, the shadow price approach, the nucleolus approach. We also show results when using a simple "volume" based allocation method which often is the one used in practice. Finally, we present the retained approach named the equal profit method. These are described in the paper and there is also a powerpoint presentation that is used to describe models, methods and results.

\section{Experiences}

We have been playing this game with students, business people and researchers in France, Sweden, Norway, Chile and Canada. All information (PDF documents, Excel sheets and ppt presentation) is provided by the authors. We first developed version 2 of the game where 8 players are provided with the company information and on the impact of partnering with another company. For example, company 1, knows its cost, average transportation distance and the geographical location of its catchment areas and industries. Company 1 also knows the potential benefit of pairing with company $2,3,4,5,6,7$ and 8 respectively. It does not know the benefit of being part of a larger coalition. This was for us the replication of the real case as there are eight companies involved in the real case. We however found that the players with the smallest companies where rapidly put aside. The only way they could really be heard by the others was to join their force even though they did not have any incentive at first sight. Only once, as a "larger" player, would the others start discussing with them. This was difficult for the student to realize; very few participants saw the potential of this strategy and were capable of using its power into the negotiation process.

Running the game in different countries permitted us to capture cultural differences. These observations cannot be generalized but are interesting to discuss here as they illustrate strategies in dealing with the case. North Americans tend to build their coalition one by one, this is in opposition to Scandinavians who typically start with the grant coalition and rarely eliminate a company from the grant coalition. Participants from France and Chile have used mixed strategies mainly based on the relations - pairing 
with their friends. In Chile, one group decided to eliminate the smallest company and gave the player the responsibility of mediating the grand coalition. These are only some examples of how the participants approach the challenges of this game and again no generalization is possible. In this game the players focus more on coalition building than on designing the sharing mechanism.

We then developed version 1 of the game. This version is dealing with only four companies and provides more information. Each player knows the potential benefit of paring with one, two and three company. The players are rapidly challenged by the fact that no equilibrium exists and that they need to negotiate an incentive to get the maximum out of the grant coalition (four companies). The discussions are easier to manage than in version 2 of the game as only four players are involved in each group. The players focus more on sharing mechanism than on coalition building. We have also developed an Excel sheet for this version to illustrate the results and characteristics of the most common sharing principles.

\section{Conclusions}

Collaboration in supply chain is raising interest from the academic and industrial communities. It is seen as a new approach to increase the value created through better cross-chains coordination. However, most agree on the fact that establishing efficient and sustainable collaborations requires highly skilled and competent people. This is why we developed this game.

Business games are often used for developing complex competences. This is the case of this game as the participants are integrating advanced knowledge on game theory as well as developing their negotiation skills.

To be efficient, business games need to be simple and meaningful. The game proposed is focusing on two aspects of collaboration in logistics: coalition building and sharing mechanism. It is simple to explain and to run. Moreover, the game builds on a real industrial case providing a meaningful background in terms of the data (e.g. maps, costs, distances and volumes) and human behaviors. It also shows that the theories learned through the exercise are relevant to students.

\section{References}

1. Allon, G., Van Mieghem, J.A.: The Mexico-China Sourcing Game: Teaching Global Dual Sourcing. INFORMS Trans. of Ed. 10(3), 105-112 (2010)

2. Ben-Zvi, T., Carton, T.C.: From Rhetoric to Reality: Business games as Educational Tools. INFORMS Trans. of Ed. 8(1), 10-18 (2007)

3. Forsberg, M., Frisk, M., Rönnqvist, M.: FlowOpt - a decision support tool for strategic and tactical transportation planning in forestry. Int. J. of For. Eng. 16, 101-114 (2005)

4. Frisk, M., Göthe-Lundgren, M., Jörnsten, K., Rönnqvist, M.: Cost allocation in collaborative forest transportation. Eur. J. of Oper. Res. 205, 448-458 (2010)

5. Griffin, P.: The Use of Classroom Games in Management Science and Operations Research. INFORMS Trans. of Ed. 8(1), 1-2 (2007)

6. Simchi-Levi, D., Kaminsky, P., Simchi-Levi, E.: Designing and Managing the Supply Chain, 2nd edn. Irwin/McGraw-Hill, New York (2003) 
7. Sniedovich, M.: OR/MS Games: 1. A Neglected Educational Resource. INFORMS Trans. of Ed. 2(3), 86-95 (2002)

8. Sterman, J.: Modeling managerial behaviour: Misperceptions of feedback in a dynamic decision making experiment. Man. Sci. 35(3), 321-339 (1989)

9. Talluri, K.: The Customer Valuations Game as a Basis for Teaching Revenue Management. INFORMS Trans. Ed. 9(3), 117-123 (2009)

10. Wood, S.C.: Online Games to Teach Operations. INFORMS Trans. Ed. 8(1), 3-9 (2007) 